\title{
Effects of drought on the physiological parameters of fruit crops leaves
}

\author{
Alisa Mishko*, Maria Sundyreva, Rimma Zaremuk, Nina Mozhar, and Eugene Lutskiy \\ Federal State Budget Scientific Institution «North Caucasian Federal Scientific Center of Horticulture, \\ Viticulture, Wine-making», 39 str. 40 Let Pobedy, Krasnodar, 350901, Russia
}

\begin{abstract}
Development of the modern horticulture is impossible without studying the adaptive capabilities of crops cultivars and hybrids. Drought is one of the major factors, which negatively influence on plants growth and development in summer period. This stress factor results in disruption of the photosynthetic apparatus, changing the electron flux, which facilitates the accumulation of free radicals. Activation of plant defense systems can suppress the development of oxidative stress. In this research, the physiological and biochemical characteristics of leaves under drought stress of different cultivars of pear, plum and cherry growing in the Krasnodar region during summer period were studied. It was found that in the driest month - august, the majority of cultivars were in the-oxidative stress state, which resulted in an increase of the malondialdehyde content. The greatest adaptive potential to drought was noted in the pear cultivars Williams and Flamenco, as well as among the cherry cultivars there were Volshebnitsa and Sashenka. The better drought resistance characteristics among plum cultivars were detected in the control cultivar Stenley According to the obtained data, it was found that the decrease of chlorophylls content in leaves correlated with the increase of the carotenoid and malondialdehyde contents.
\end{abstract}

\section{Introduction}

Modern horticulture faces many challenges, caused by rapidly increasing impact of biotic and abiotic stress factors. In the south one of the main abiotic stress factors is drought, which slows down-growth and development of fruit crops, as well as their productivity. Moreover, a decrease of fruit crops productivity caused by drought is noted all over the world $[1,2]$.

In the conditions of the Krasnodar region, researchers have noted a change in the temperature regime towards an increase in abnormally high positive temperatures since the middle of the 20th century. In this connection, the selection of fruit cultivars, taking into account their resistance to drought and high temperatures, is a particularly important and promising direction in breeding resistance cultivars and hybrids.

Drought is a physiological form of water deficit, where soil water becomes insufficient for the plant, which leads to different disorders at the molecular, cellular and tissue levels [3]. There are three types of strategies for plant response to water deficit: drought escape, drought avoidance and drought tolerance [1, 4]. In the first strategy, plants complete its life cycle or stops its growth and development before drought, thereby avoiding the impact of this stress 
factor. The drought avoidance strategy is based on increasing water absorption and reducing water loss through the operation of the stomata and root system. Drought tolerance allows the plant to negate low water content in the tissue, regulating osmotic pressure and activating the antioxidant defense system. The last two strategies characterize both different ecological origin of plants and different stages of the response to drought, depending on its duration. With a short-time water deficit, it is enough for plants to increase the absorption capacity of the root system and reduce the photosynthetic activity of the leaves. If the drought continues for a long period, other adaptation mechanisms will take part in the defensive measures against stress, providing the accumulation of protective proteins and low molecular weight osmolytes, the detoxification of reactive oxygen species (ROS) by the synthesis of antioxidant enzymes, and the increase of genes expression for drought tolerance [2, 3].

Thus, to assess the plant's resistance to water deficit the varied characteristics are taken into account. For instance, there are the indicators of photosynthetic activity of leaves, the activity of both enzymatic defense mechanisms aimed at neutralizing oxidative stress and non-enzymatic ones. Also, these includes the parameters of the water regime and the gene expression of transcription factors that perform key regulatory functions. For example, in transgenic apple forms characterized by overexpression of the transcription factor MdNAC1, researchers noted higher levels of water and pigments in leaves relative to wild type [5]. At the same time, values of electrolyte leakage and ROS concentrations decreased under drought conditions. For apple cultivar Fuji, the photosynthetic characteristics of the leaf were investigated at various levels of water deficit, which decreased with increasing aridity of growing conditions, while the accumulation of ROS and the activity of antioxidant enzymes, on the contrary, increased [6]. In another study, the authors performed transcriptome and metabolome analysis of cherry rootstocks in order to identify the main molecular protein markers of drought resistance, which included phenylalanine, quinic acid, asparagine, etc. [7]. The identification of adaptive characteristics is currently carried out according to the morphological parameters of the shoot and leaf together with physiological and biochemical indicators. Hence, using the pear as an example, cultivars more resistant to drought were identified, differing in the lowest growth rates of the shoot [8].

The aim of this research is to study some physiological and biochemical leaf characteristics of different cultivars of plum, cherry and pear, growing in the Prikubanskay fruit-growing zone in the Krasnodar region under drought stress, and to identify the most drought-resistant cultivars.

\section{Materials and methods}

Research was carried out with cultivars of the North Caucasian Federal Scientific Center of Horticulture, Viticulture, Wine-making breeding and introduced cultivars of the main fruit crops (pear, plum, cherry), which occupy a significant share of the area in the structure of gardening in the South region of Russia. The cultivars of Russian breeding were pear cultivar Flamenco, plum cultivars Gertsog and Podruga, cherry cultivars Alaya, Volshebnitsa and Sashenka. As a control, there were zoned cultivars $(\mathrm{z})$ for the conditions of the southern region. Pear cultivars - Flamenco, Conference, Williams (z); plum cultivars - Gertsog, Podruga, Stanley (z); cherry cultivars - Alaya (z), Volshebnitsa and Sashenka. The pear garden was planted in 2007, planting distances were $5 \times 2 \mathrm{~m}$; the plum garden - 2011, planting distances were $5 \times 3 \mathrm{~m}$, the cherry garden - 2005, planting distances were $4 \times 2 \mathrm{~m}$.

For the experiment, leaves were selected from annual shoots of pear, plum and cherry cultivars growing in the Prikubanskaya fruit-growing zone of the Krasnodar region during the period of exposure to abnormally high air temperatures (July and August 2020).

The weather conditions of studied period were unstable: the average air temperature in July $\left(+25,4^{\circ} \mathrm{C}\right)$ exceeded the average annual indicators by $5-6,5^{\circ} \mathrm{C}$, the amount of 
precipitation increased by two times relative to the norm value $(105 \mathrm{~mm})$. In August, there was a significant decrease in precipitation to $10.6 \mathrm{~mm}$ at high mean air temperature. Weather data were taken for the period July-August 2020 from the Krasnodar weather station (Kruglik, No. 34927).

Experiments of the drought effect on selected samples were carried out under laboratory conditions by placing freshly harvested leaves in a closed glass container on dry filter paper for 1 hour at room temperature. Such experiment model was chosen according to recent studies of oxidative stress development in apple leaves under abiotic stress factor $[9,10]$.

After stress, the leaves were immediately used for further analysis. Determination of relative water content (RWC) of leaves was carried out according to the generally accepted method [11]. The content of pigments - chlorophylls (Chl $a, \mathrm{Chl} b$ ) and carotenoids (Car) - was estimated by the spectrophotometric method [12]. The level of oxidative stress under artificial drought stress was determined by the accumulation of malondialdehyde (MDA), which is one of the end products of oxidation of polyunsaturated fatty acids of cell membranes [13].

The present research was carried out on the instrumentation of the Center for Collective Using NCFSCHVW. All obtained data are presented as means and their errors. To compare the mean values, the Tukey's test was applied with significant differences less than 0.05 using Statistica 13.3 software. Factor analysis was identified the most significant parameters of leaf, showing the variety of the obtained results.

\section{Results and discussion}

In 2020 , the hottest month was July, the average air temperature of which was $+25,4^{\circ} \mathrm{C}$, and the maximum temperature was $+37,8^{\circ} \mathrm{C}$, while for August, the value of less than $+24^{\circ} \mathrm{C}$ was recorded, with a maximum equals to $+34,7^{\circ} \mathrm{C}$. The relative humidity in July was $63 \%$, in August $-54 \%$. The amount of precipitation in July was $105 \mathrm{~mm}$, in August it dropped to $11 \mathrm{~mm}$. Thus, the relative humidity and precipitation in August decreased by 8 and $81 \%$, respectively, compared to the previous month. It makes possible to determine August as the driest month during the researching period.

Analysis of leaf relative water content, exposed to the artificial drought stress summer months showed no significant differences were noticed between the each fruit crop. Average value of this parameter was $69 \%$. In a general comparison of all studied cultivars, the lowest value was noted in July for the control pear cultivar Williams, which did not exceed $63 \%$. In August, three pear cultivars had the maximum RWC. The values of pear cultivars were scattered from 78 to $82 \%$, while RWC of plum and cherry was on average $\sim 70 \%$.

In terms of chlorophyll content in July, cultivar differences were found in plum where chlorophyll $a$ content was maximum in the control cultivar Stenley $(1,7 \mathrm{mg} / \mathrm{g}$ fresh weight $((\mathrm{FW}))$. It was the highest value among the studied crops for this month. (Fig. 1). The maximum level of chlorophyll $b$ was observed in cherry cultivar Volshebnitsa $(0,7 \mathrm{mg} / \mathrm{g}$ FW). In August, pear cultivar Flamenco had maximum chlorophyll $a$ of 1,4 mg/g FW. There were no significant differences in chlorophyll $b$ content in this month among studied cultivars. On average, the values of this parameter were $0,4 \mathrm{mg} / \mathrm{g} \mathrm{FW}$. To compare the values of total chlorophyll in the summer period, no significant differences were found (Fig. 2). In July, this parameter reached 1,7 mg/g FW, in August - 1,4 mg/g FW, with the exception of significant high values of pear cultivar Flamenco, which amounted to 2,3 $\mathrm{mg} / \mathrm{g} \mathrm{FW}$. 


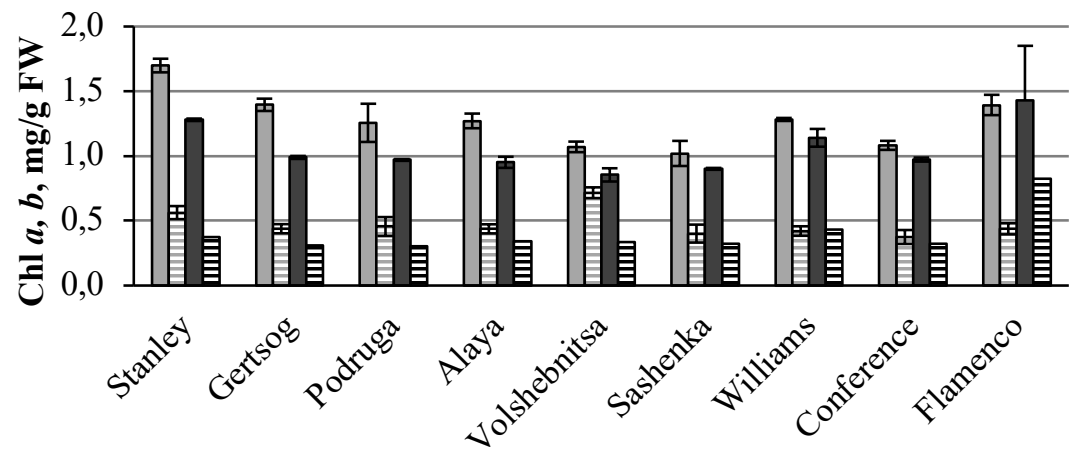

$\square$ July Chl a $\boxminus$ July Chl b $\square$ August Chl a 目August Chl b

Fig. 1. Chlorophyll $a$ and $b(\mathrm{Chl} a, \mathrm{Chl} b)$ in the leaves of different cultivars of pear, plum, and cherry under artificial drought stress

The content of carotenoids in the leaves of the control plum cultivar Stanley significantly increased in July under artificial drought stress compared with cultivars Gertsog and Podruga (Fig. 2). In cherry cultivars Alaya and Sashenka, a significant increase in this parameter was recorded in relation to the indicators of cultivar Volshebnitsa. No cultivar differences were found in August for each individual crop. Comparing the values of two summer months, it was observed that in August the content of carotenoids was higher than in July by $26 \%$ for cultivar Volshebnitsa, by less than 5\% for cultivar Sashenka and by $7 \%$ for the control pear cultivar Williams.

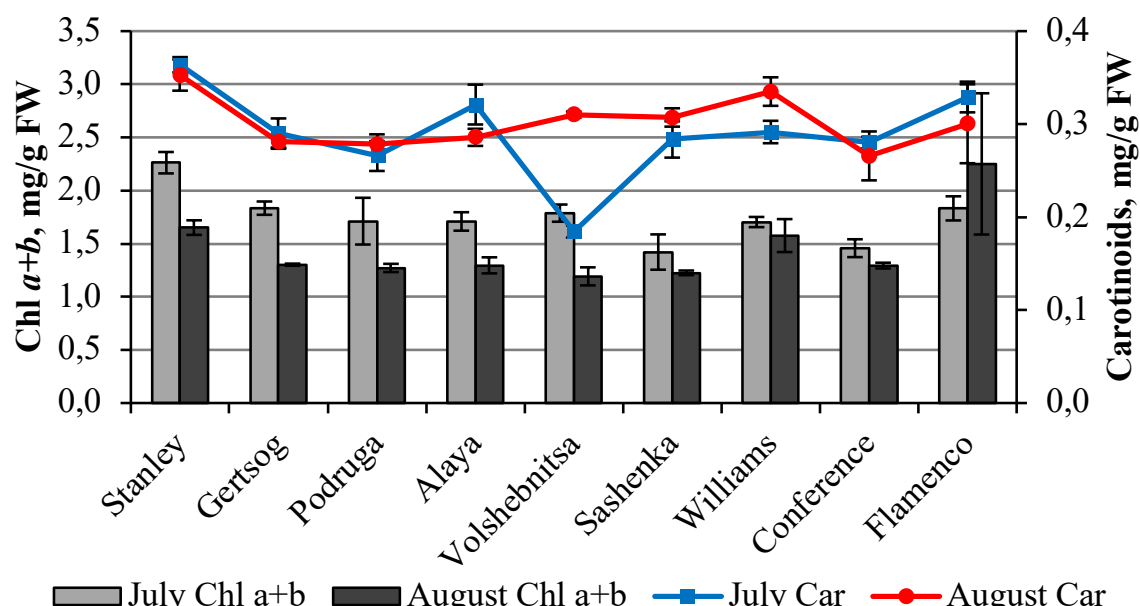

Fig. 2. Total chlorophyll $a, b(\mathrm{Chl} a+b)$ and carotenoids (Car) content in the leaves of different cultivars of pear, plum, and cherry under artificial drought stress

The maximum variation by cultivars was revealed when comparing indicators of MDA in leaves. Among plum cultivars, the maximum and minimum peaks were recorded for the control cultivar Stenley in August and July, respectively (Fig. 3). The control cultivar Alaya had the highest MDA in cherry leaves. The control cultivar Williams was a higher value of MDA compared to other pear cultivars. Based on the obtained data, in the driest month, the control cultivars of the investigated fruit crops had the maximum MDA values, which is an indicator of activation oxidative processes in leaf cells. 


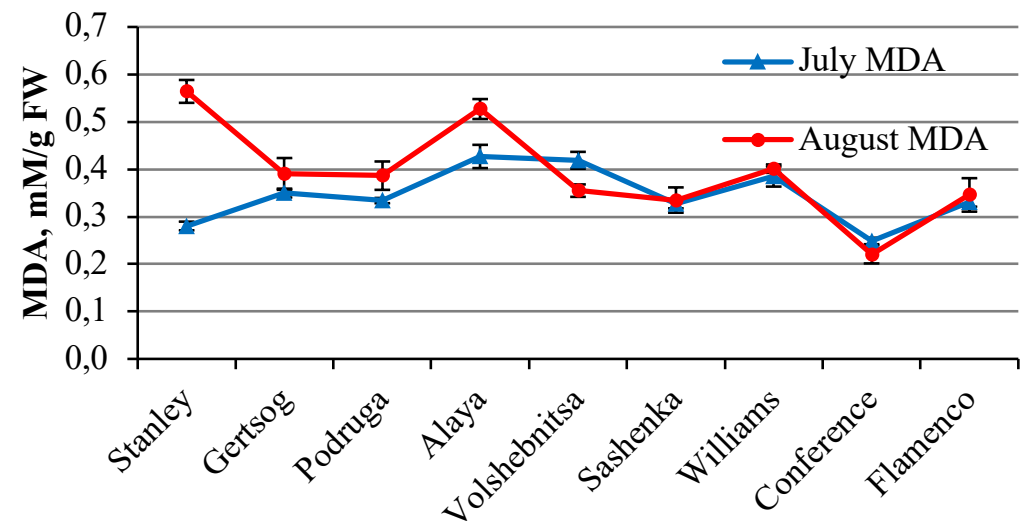

Fig. 3. Malondialdehyde (MDA) content in the leaves of different cultivars of pear, plum, and cherry under artificial drought stress

Summarizing the presented results, we can conclude that in August, the driest month, the content of carotenoids under artificial drought stress significantly increased only in leaves of two cherry cultivars Volshebnitsa, Sashenka and pear cultivar Williams. Total chlorophyll, chlorophyll $a$ and $b$ in leaves were reduced in all cultivars, except Flamenco. The MDA value increased in the majority of cultivars in August. All these data indicate an increase of the stress impact against the background of more arid growing conditions. Based on the results of factor analysis, two groups of parameters were identified, the proportion of variance of which was $51 \%$ and $24 \%$. The first group included the content of chlorophylls $a$ and $b$ and total chlorophyll, and the second included carotenoids and MDA. Consequently, two distinguished factors explain $75 \%$ of the total diversity of values of the investigated fruit crops.

\section{Conclusion}

According to the obtained data, the effect of artificial drought in the driest month August had a greater negative effect on the studied cultivars in comparison with July weather conditions. This is reflected in a decrease in the content of pigments and MDA accumulation, which is a marker of oxidative stress.

The leaves of pear cultivars Williams, Conference and Flamenco under stress conditions in August had the higher RWC and pigment values and the lower MDA values, which corresponded to a high adaptive potential to drought. A rapid increase of carotenoids, that may neutralize the action of free radicals formed during oxidative stress, was recorded in two cherry cultivars Volshebnitsa and Sashenka and in the control pear cultivar Williams in August. It characterizes their high adaptive capabilities in the absence of MDA increase [14, $15]$.

Thus, according to obtained preliminary data for the studied summer period, among pear cultivars, the control cultivar Williams with a high content of carotenoids and cultivar of Russian breeding Flamenco, which had the maximum chlorophyll values, proved to be the most drought resistant cultivars. To comparing cherry cultivars, the cultivars Volshebnitsa and Sashenka were distinguished by a higher level of adaptation indicators. Among the plum cultivars, the control cultivar Stenley was characterized by a higher content of pigments in the leaves. 


\section{References}

1. S. Basu, V. Ramegowda, A. Kumar, A. Pereira, F1000Res., 5, 1554 (2016) https://doi.org/10.12688/f1000research.7678.1

2. R. Joshi, S.H. Wani, B. Singh, A. Bohra, Z.A. Dar, A.A. Lone, A. Pareek, S.L. SinglaPareek, Front. Plant Sci., 7, 1029 (2016) https://doi.org/10.3389/fpls.2016.01029

3. S. Kumar, S. Sachdeva, K. V. Bhat, S. Vats, In: S. Vats (ed.) Biotic and Abiotic Stress Tolerance in Plants, 1-25 (Springer Nature Singapore Pte Ltd., 2018) https://doi.org/10.1007/978-981-10-9029-5 1

4. N. Osmolovskaya, J. Shumilina, A. Kim, A. Didio, T. Grishina, T. Bilova, O. A. Keltsieva, V. Zhukov, I. Tikhonovich, E. Tarakhovskaya, A. Frolov, L. A. Wessjohann, Int. J. Mol. Sci., 19, 4089 (2018) https://doi.org/10.3390/ijms19124089

5. D. Jia, Q. Jiang, S. van Nocker, X. Gong, F. Ma, Plant Physiol. Biochem., 139, 504-512 (2019) https://doi.org/10.1016/j.plaphy.2019.04.011

6. Z. Wang, G. Li, H. Sun, L. Ma, Y. Guo, Z. Zhao, H. Gao, L. Mei, Biol. Open, 7(11), bio035279 (2018) https://doi.org/10.1242/bio.035279

7. T. Wan, Y. Feng, C. Liang, L. Pan, L. He, Y. Cai, Biology, 10(3), 201 (2021) https://doi.org/10.3390/biology10030201

8. M. Tatari, A. Jafari, M. Shirmardi, M. Mohamadi, Int. J. Fruit Sci., 20(4), 837-854 (2020) https://doi.org/10.1080/15538362.2019.1697410

9. Z. Wei, T. Gao, B. Liang, Q. Zhao, F. Ma, C. Li, Int. J. Mol. Sci., 19(1), 316 (2018) https://doi.org/10.3390/ijms19010316

10. Y. Mei, H. Sun, G. Du, X. Wang, D. Lyu, Sci. Hort., 274, 109676 (2020) https://doi.org/10.1016/j.scienta.2020.109676

11. H. Xue, F. Zhang, Z.H. Zhang, J.F. Fu, F. Wang, B. Zhang, Y. Ma, Sci. Hort., 190, 2430 (2015) https://doi.org/10.1016/j.scienta.2015.04.009

12. A.R. Bonyanpour, B. Jamali, Adv. Hort. Sci., 34(3), 265-276 (2020) https://doi.org/10.13128/ahsc-8283

13. S. Wang, D. Liang, C. Li, Y. Hao, F. Ma, H. Shu, Plant. Physiol. Biochem., 51, 81-89 (2012) https://doi.org/10.1016/j.plaphy.2011.10.014

14. E.K. Mibei, J. Ambuko, J.J. Giovannoni, A.N. Onyango, W.O. Owino, Food Sci. Nutr., 5(1), 113-122 (2017) https://doi.org/10.1002/fsn3.370

15. A. Sharma, J. Wang, D. Xu, S. Tao, S. Chong, D. Yan, Z. Li, H. Yuan, B. Zheng, Sci. Total Environment., 713, 136675 (2020) https://doi.org/10.1016/j.scitotenv.2020.136675 